\title{
DANO AMBIENTAL: DISCUSSÃO SOBRE A TUTELA JURÍDICA
}

\section{Munir Jorge Felício ${ }^{1}$}

\section{Fúlvia Letícia Perego Silva²}

RESUMO: O século XX foi marcado pelo desenvolvimento acentuado das mais diversas tecnologias e pelo nascer da globalização. Nesse cenário, a questão ambiental tem um papel fundamental e essencial na preservação do Planeta, especialmente pelo fato de que sua ocorrência desconhecer fronteiras geográficas. Conhecer e discutir sobre o dano ambiental é fundamental como atividade científica e política diante desse cenário. Durante séculos governos e empresas exploram recursos naturais de forma desenfreada, em razão de uma economia predominantemente consumista. Tal condição provoca enorme dificuldade no controle de danos ambientais em todos os cantos do mundo. Com a tomada de consciência dos problemas ambientais a serem enfrentados - o que se deu a partir da segunda metade do século XX - buscou-se o fortalecimento do Direito Internacional como forma de solução de conflitos e adoção de medidas eficazes à preservação do Planeta. Entre avanços e retrocessos, é possível afirmar que alguns progressos foram alcançados em âmbito mundial. Todavia, incumbe a cada Estado, antes de tudo, adotar uma política eficiente de proteção ao meio ambiente dentro de seus limites territoriais, para que uma integração global satisfatória seja atingida. No Brasil, a primeira legislação de proteção ao meio ambiente surgiu na década de 1980, com a Lei n. 6.938/81, que criou a Política Nacional do Meio Ambiente. Mas foi em 1988, com a entrada em vigor da Constituição Federal, que o meio ambiente passou a ser tutelado como um direito fundamental da sociedade.

1 Doutor, docente do Mestrado em Meio Ambiente e Desenvolvimento Regional - MMADRE UNOESTEMADRE, munir@unoeste.br

${ }^{2}$ Advogada, fulvialeticia.adv@uol.com.br 
Palavras-chave: questão ambiental; desenvolvimento; capitalismo; dano ambiental.

\section{INTRODUÇÃO}

Nem todo impacto ambiental pode ser considerado um dano ambiental, todavia ambos estão atrelados à existência humana na terra e, por conseguinte, não constituem especificidades atuais. Todavia, como ressalta Milaré (2011) a devastação ambiental "é um fenômeno que acompanha o homem desde os primórdios de sua história. Apenas a percepção jurídica desse fenômeno - até como consequência de um bem jurídico novo denominado 'meio ambiente' - é que é recente” (MILARÉ, 2011, p.23).

Como o conceito de dano ambiental é um pressuposto indispensável para a teoria jurídica da responsabilidade ambiental, vários pesquisadores se empenharam na construção desse conceito na tentativa de ampliar a compreensão que a realidade exige, como fizeram Antunes (2013) e Leite (2012), entre outros. Para Antunes (2013)

O dano é o prejuízo injusto causado a terceiro, gerando obrigação de ressarcimento. A ação ou omissão de um terceiro é essencial. Desnecessário dizer que, no conceito, somente se incluem as alterações negativas, pois não há dano se as condições forem alteradas para melhor, sem prejuízo. É a variação, moral ou material, negativa que deverá ser, na medida do possível, mensurada de forma que se possa efetivar o ressarcimento (ANTUNES, 2013, p. 539).

Leite (2012) entende que

Dano é toda ofensa a bens ou interesses alheios protegidos pela ordem jurídica. O interesse, nesta concepção, representa a posição de uma pessoa, grupo ou coletividade em relação ao bem suscetível de satisfazer-lhe uma necessidade. Bem deve ser entendido, em sentido amplo, como o meio de satisfação de uma necessidade. Pelo que se depreende desta definição, dano abrange qualquer diminuição ou alteração de bem destinado à satisfação de um interesse. Isso significa, como regra, que as reparações devem ser integrais, sem limitação quanto à sua indenização, compreendendo os danos patrimoniais e extrapatrimoniais. (...) Na verdade, dano é um elemento essencial à pretensão de uma indenização, pois sem este elemento não há como articular uma obrigação de reparar. (LEITE, 2012, p. 91).

Para o mundo jurídico o dano se constitui um dos alicerces essenciais da responsabilidade civil e, por essa razão, sua existência indica a ocorrência de lesão a um bem jurídico tutelado, o que pode sugerir o debate da seguinte questão: sem lei não há 
dano? Questões como essa impulsionam os pesquisadores a dirimir as dificuldades quanto a definição de dano ambiental, principalmente na literatura jurídica moderna brasileira por ser um conceito aberto, assim como é o 'meio ambiente'.

Dano ambiental constitui qualquer prejuízo causado diretamente aos recursos ambientais, com consequente degradação cuja abrangência atinge essencialmente o equilíbrio ecológico e, a consequente qualidade de vida. Essa concepção de dano ambiental não pode estar divorciada da visão ampla de meio ambiente onde está presente o conjunto de elementos naturais, artificias e culturais. Todavia, a ambivalência do conceito precisa ser desfeita como explica Leite (2012), pois suas alterações além de serem nocivas ao meio ambiente podem, concomitantemente transformar as condições ideias atingindo diretamente a saúde das pessoas e de seus interesses, uma vez que o

Dano ambiental significa, em uma primeira acepção, uma alteração indesejável ao conjunto de elementos chamados meio ambiente, como, por exemplo, a poluição atmosférica; seria, assim, uma lesão ao direito fundamental que todos têm de gozar e aproveitar do meio ambiente apropriado. Contudo, em sua segunda conceituação, dano ambiental engloba os efeitos que esta modificação gera na saúde das pessoas e em seus interesses (LEITE, 2012, p. 92).

Corroborando com as considerações de Leite (2012), Fiorillo (2013) também esclarece que

Ocorrendo lesão a um bem ambiental, resultante de atividade praticada por pessoa física ou jurídica, pública ou privada, que direta ou indiretamente seja responsável pelo dano, não só há a caracterização deste como a identificação do poluidor, aquele que terá o dever de indenizá-lo (FIORILLO, 2013, p. 94).

Juridicamente, portanto, o dano ambiental constitui em determinada ação ou omissão que, necessária e obrigatoriamente cause qualquer prejuízo em condições, leis, influências, interações internas e externamente na ordem física, química e biológica impedindo o livre percurso das mais diversas formas de vida "em quaisquer de suas formas" (ANTUNES, 2013, p. 539).

\section{A JURIDICIDADE DO DANO AMBIENTAL EM COMPARAÇÃO COM O DANO TRADICIONAL}


Para Leite (2012), a tentativa de comparação do dano ambiental, com suas especificidades, cria um grande paradoxo em relação ao dano tradicional, do direito civil, dado o seu caráter interindividual. As concepções clássicas e as caraterísticas tradicionais do dano passam por uma nova configuração, quando se discute a lesão ambiental, pois esta pressupõe uma visão muito menos individualista. Convém destacar, os principais elementos que comparados trazem uma visão clara dos problemas referentes à juridicidade entre dano ambiental e o tradicional:

1. O dano tradicional, conforme já dito, está ligado à pessoa e aos seus bens individuais, enquanto o ambiental é basicamente difuso, mas também pode gerar um dano ambiental reflexo, isso é, quando a lesão, além de atingir os componentes ambientais, incide nos indivíduos.

2. A lesão tradicional atinge a pessoa e sua personalidade, já o dano ambiental lesa primordialmente um interesse difuso e não exclusivo, mas sim um bem de uso comum pertencente a toda coletividade e que diz respeito à qualidade de vida.

3. A certeza é uma das características do dano tradicional, pois não há duvida de que a lesão ocorreu, sendo esta clara, definida e quase sempre visível. Por seu lado, a lesão ambiental pode ser incerta, pois muitas vezes é de difícil constatação. Como exemplo, tem-se a poluição atmosférica, que pode atingir o componente ambiental e as pessoas, mas denota uma incerteza quanto à sua concretude.

4. A lesão individual é sempre atual. Já a ambiental pode ser transtemporal e cumulativa, como exemplo tem-se o efeito estufa, a chuva ácida e muitos outros.

5. A lesão tradicional é subsistente, isto é, ela é permanente e clara. De outro lado, a lesão ambiental tem como característica ser gradativa, levando em consideração a causas e efeitos.

6. A anormalidade é característica da lesão interindividual. Já o dano ambiental pode decorrer de uma anormalidade, mas existe ou pode existir uma tolerância social do dano. O exemplo claro desta hipótese de tolerância social é o avião, que, como se sabe, polui bastante, mas não incide uma sanção de direito sobre essa atividade, pois a sociedade aceita ou tolera esta lesão.

7. A causalidade do dano tradicional é bem mais fácil de comprovação, pois existe facilidade de se apurar o liame de causalidade existente entre o autor e réu, basicamente por serem certos os envolvidos. No que tange à lesão ambiental, a imputação da causalidade é bem mais tormentosa, como se verá posteriormente nesta obra. Este fato se deve principalmente, porque muitas vezes a poluição é causada por vários agentes, sem que se possa determinar a parcela de lesão de cada um.

8. A prescrição da lesão individual tradicional e reflexa dos componentes ambientais tem prazo determinado para ser questionada em juízo, conforme estipula o Código Civil. Por seu turno, a lesão ao bem difuso tem como característica a imprescritibilidade, conforme será tratado mais especificamente posteriormente.

9. Não há discussão jurídica sobre a possibilidade do dano moral individual e este está ligado à dor da pessoa em seu sentido mais lato e físico. De outro lado, a 
lesão aos danos morais e extrapatrimoniais de caráter difuso, conforme será visto, está relacionada à qualidade de vida, valores coletivos ou em relação a valores intrínsecos da natureza, que refletem na coletividade.

10. A prova a ser levada a juízo é mais fácil em relação aos danos tradicionais. Já no que tange à lesão difusa, considerando sua complexidade, há necessidade do afrouxamento desta, considerando as dificuldades. Por esse motivo, incide a verossimilhança, a probabilidade e outros mecanismos.

11. A lesão tradicional está conectada aos bens e direitos da personalidade e dignidade do individuo. Por seu turno, o dano ambiental está ligado à qualidade de vida e outros valores, que não são exclusivos de ninguém, pois pertencem a todos.

12. No direito tradicional, o direito adquirido e a estabilidade do ato jurídico são aceitos normalmente. Em oposição, para a proteção dos valores ambientais difusos, faz-se necessária a intervenção de novos princípios, tais como o da precaução, prevenção, poluidor-pagador e reparação integral do dano. Desta forma, na lesão ambiental tem-se a incidência do cuidado e da prudência modificando juridicidade do direito adquirido, levando em conta a solidariedade intergeracional e a relação com o futuro e uma responsabilidade compartilhada em face do bem comum. (LEITE, 2012, p. 97-98).

\section{A DUPLA FACE DO DANO AMBIENTAL}

Milaré (2011, p. 1120) identifica "uma dupla face na danosidade ambiental, tendo em vista que os seus efeitos alcançam não apenas o homem, como, da mesma forma, o ambiente que o cerca." Podendo se distinguir em:

(i) o dano ambiental coletivo ou dano ambiental propriamente dito, causado ao meio ambiente globalmente considerado, em sua concepção difusa, como patrimônio coletivo; e (ii) o dano ambiental individual que atinge pessoas certas, através de sua integridade moral e/ou de seu patrimônio material particular (MILARÉ, 2011, p. 1.120).

O primeiro (i), diz respeito aos danos ambientais causados ao meio ambiente lato sensu, repercutindo em interesses que podem ser coletivos stricto sensu (são "os transindividuais de natureza indivisível de que seja titular grupo, categoria ou classe de pessoas ligadas entre si ou com a parte contrária por uma relação jurídica base") ou difusos (são "os transindividuais de natureza indivisível, de que sejam titulares pessoas indeterminadas e ligadas por circunstancias de fato"), nos termos do art. 81, parágrafo único, I e II, da Lei 8.078/1990 - Código de Defesa do Consumidor.

Neste caso, quando cobrado e havendo indenização, o valor vai para um Fundo, cujos recursos serão destinados à reconstituição dos bens lesados, nos termos do art. 13, da Lei 7.347/1985. A sua tutela pode se dar através de ação civil pública ou de 
outros instrumentos processuais adequados, cabendo ao membro do Ministério Público a iniciativa das providencias cabíveis, seja para garantir a reparação do dano ambiental coletivo ou mesmo para prevenir a sua ocorrência.

O segundo (ii), diz respeito ao dano ambiental individual, também chamado de dano ricochete ou reflexo que, "ao afetar desfavoravelmente a qualidade do meio, repercute de forma reflexa sobre a esfera de interesses patrimoniais ou extrapatrimoniais de outrem" (MILARÉ, 2011, p. 1.122). A vítima do dano ambiental pode buscar a reparação do dano sofrido, por meio de uma ação indenizatória de cunho individual. Dessa forma, um mesmo dano ambiental pode acarretar, além da responsabilidade objetiva em razão de dano à coletividade, a reparação do dano ambiental reflexo. Portanto, há autonomia entre os danos ambientais coletivos e individuais.

\section{CARACTERÍSTICAS DO DANO AMBIENTAL}

O dano ambiental, intensificado com o advento da sociedade industrial, tem características próprias, tais como observa Milaré (2011):

a) a ampla dispersão de vítimas: se caracteriza pela pulverização de vítimas, em virtude do tratamento que o direito dá ao ambiente, qualificado nos termos do artigo 225, caput, da Constituição Federal como "bem de uso comum do povo";

b) a dificuldade inerente à ação reparatória: se caracteriza pela difícil reparação, pois jamais se reconstituirá a integridade ambiental ou a qualidade do meio que foi afetado. A prevenção é a melhor, quando não, a única solução;

c) a dificuldade da valoração: se caracteriza pela difícil valoração, pois a estrutura sistêmica do meio ambiente dificulta ver até onde e até quando se estendem as sequelas do estrago. Com o advento da Lei 8.884/1994, no art. 88, tornou-se ainda mais complexo a valoração, posto que também os danos morais coletivos passaram a ser objetos de ações de responsabilidade civil em matéria de tutela de interesse transindividual (MILARÉ, 2011, p. 1.122).

\section{O DANO AMBIENTAL NO ORDENAMENTO JURÍDICO BRASILEIRO}

O legislador brasileiro não definiu expressamente dano ambiental, mas ofereceu suas principais características de forma abrangente e pouco objetiva, como também associou degradação à poluição. A Lei 6.938/81 que dispõe sobre a Política Nacional do Meio Ambiente, estabelece no seu artigo $3^{\circ}$, inciso IV que poluidor "é a 
pessoa física ou jurídica, de direito público ou privado, responsável, direta ou indiretamente, por atividade causadora de degradação ambiental". Ainda, conceitua a degradação ambiental como a "alteração adversa das características do meio ambiente" (inciso II, do artigo $3^{\circ}$ da citada lei).

Assim sendo, é importante mencionar a definição legal de poluição prevista no artigo $3^{\circ}$, inciso III, da Lei 6.938/81:

III - Poluição, a degradação da qualidade ambiental resultante das atividades que direta ou indiretamente:

a) prejudicam a saúde e o bem estar da população;

b) criem condições adversas às atividades sociais e econômicas;

c) afetem desfavoravelmente a biota;

d) afetem as condições estéticas e sanitárias do meio ambiente;

e) lancem matéria ou energia em desacordo com os padrões ambientais estabelecidos.

A legislação define poluidor como a pessoa (física ou jurídica) causadora da degradação ambiental, por conseguinte, poluidor é o degradador ambiental ou a pessoa que altera adversamente as características do ambiente. $O$ tratamento legal atribuído a esses conceitos jurídicos: poluidor, poluição e degradação ambiental, dá ensejo a afirmação de que a poluição não está restrita à alteração do meio natural, portanto, o meio ambiente a ser considerado pode ser tanto o natural, quanto o cultural e o artificial. Logo, o dano é um pressuposto da obrigação de reparar e, consequentemente, um elemento necessário para a configuração do sistema de responsabilidade civil. Já a definição de dano ambiental abrange qualquer lesão ao bem jurídico-meio ambiente, causada por atividades ou condutas de pessoas físicas ou jurídicas.

Após análise na lei brasileira, Leite (2012) concluiu que:

O dano ambiental deve ser compreendido como toda lesão intolerável causada por qualquer ação humana (culposa ou não) ao meio ambiente, diretamente, como macrobem de interesse da coletividade, em uma concepção totalizante, e indiretamente, a terceiros, tendo em vista interesses próprios e individualizáveis e que refletem no macrobem (LEITE, 2012, p. 101-102).

Ao tratar da danosidade ambiental, Milaré (2011), ressalta a reação jurídica, chamado por ele de "materialização do princípio da responsabilidade integral do degradador, que o sujeita, cumulativamente, às sanções repressivas e reparatórias". Um 
ato atentatório ao ambiente poderá ter repercussão no ordenamento jurídico de três maneiras distintas: sanções administrativas, sanções criminais e sanções civis.

Além do artigo 935 do Código $\mathrm{Civil}^{3}$ estabelecer o principio da independência da responsabilidade civil em relação à criminal, a norma constitucional já o havia incorporado para fins de defesa do meio ambiente, nos termos do paragrafo $3^{\circ}$, do artigo 225 da Constituição Federal, que prevê "as condutas e atividades consideradas lesivas ao meio ambiente sujeitarão os infratores, pessoas físicas ou jurídicas, a sanções penais e administrativas, independentemente da obrigação de reparar os danos causados". Também no mesmo diploma legal, nos termos do artigo 170, caput, e VI, a ordem econômica brasileira, "fundada na valorização do trabalho humano e na livre iniciativa" adota, entre seus princípios, a "defesa do meio ambiente". Já a Lei 9.605/1998 veio dispor sobre as sanções penais e administrativas derivadas de condutas e atividades lesivas ao meio ambiente.

Do texto constitucional depreende-se, com facilidade, que o dano ao meio ambiente tem repercussão jurídica em três esferas, sendo certo que o poluidor, por um mesmo ato, pode ser responsabilizado, alternativa ou cumulativamente, nas esferas penal, administrativa e civil. Assim, a proteção jurídica do meio ambiente atua na área preventiva, reparatória e repressiva.

Quanto ao tipo de sanção, essa pode ser de ordem moral (advertência), patrimonial (decorrente da responsabilidade civil) ou limitativa de liberdade, sendo que a responsabilidade adquire características e normas próprias dependendo do âmbito no qual se a analisa.

Assim, cada um dos três âmbitos de responsabilidade tem características próprias e é regido por normas específicas. Vale dizer mais: os três tipos de responsabilidade são independentes entre si, resultando em sanções próprias de cada tipo. Esta característica, aliás, não constitui peculiaridade do dano ambiental ou ecológico, pois qualquer dano causado a um bem de interesse público pode gerar os três tipos de responsabilidade. Convém, porém, comentar as três formas de reparação ao dano ambiental:

\footnotetext{
${ }^{3}$ Art. 935. A responsabilidade civil é independente da criminal, não se podendo questionar mais sobre a existência do fato, ou sobre quem seja o seu autor, quando estas questões se acharem decididas no juízo criminal.
} 
1) Responsabilidade Civil Ambiental: se caracteriza pelo caráter reparatório, objetivando a recomposição do status quo do meio ambiente danificado quando for possível - ou a indenização pelo dano provocado, o que deverá ser apurado através de um processo judicial de natureza civil, de competência do Poder Judiciário; a responsabilidade civil ambiental é objetiva, por força do artigo 14, $\S 1^{\circ}$, da Lei 6.938/81, tendo o ordenamento consagrado, excepcionalmente neste ponto, a teoria da responsabilidade civil objetiva, independente da comprovação de culpa ou dolo.

A responsabilidade civil objetiva foi recepcionada pela Constituição Federal de 1988, nos termos do paragrafo $3^{\circ}$, do artigo 225 da Constituição Federal, que prevê "as condutas e atividades consideradas lesivas ao meio ambiente sujeitarão os infratores, pessoas físicas ou jurídicas, a sanções penais e administrativas, independentemente da obrigação de reparar os danos causados".

Nesse sentido, o Código Civil atual, passou a adotar, juntamente com a responsabilidade subjetiva, fundada no ato ilícito e na teoria da culpa, a responsabilidade objetiva, fundada no risco da atividade, nos termos do artigo 927 do Código Civil que dispõe: "haverá obrigação de reparar o dano, independentemente de culpa, nos casos especificados na lei, ou quando a atividade normalmente desenvolvida pelo autor do dano implicar, por sua natureza, risco para os direitos de outrem.”.

Assim, "a mera existência do risco gerado pela atividade deve conduzir à responsabilização e, havendo mais de uma causa para o dano, todas serão consideradas eficientes para produzi-lo (equivalência das condições para aferição do liame causal)". Basta, dessa forma, que o dano esteja ligado à existência do "fator de risco", pois este deve ser considerado a causa do dano. (PADILHA, 2010, p. 284).

$\mathrm{Na}$ atual sociedade de risco, o sistema de responsabilidade adotado pela Constituição Federal faz incidir a responsabilidade objetiva a qualquer tipo de atividade que gera dano ambiental e não somente as atividades perigosas. Como o dano ambiental é indivisível nos termos do artigo $3^{\circ}$. IV, da Lei 6.938/1981, a responsabilidade civil é integral e solidária, pois todos aqueles que concorrem para o dano, de forma direta ou indireta, são responsáveis pela sua reparação. É possível, no entanto, a ocorrência da responsabilização mesmo diante da existência de licenciamento ambiental e observância de padrões de qualidade ambiental. 
Ressalte-se que, "a responsabilidade civil objetiva possui, além da função reparadora de reconstituir e/ou indenizar os prejuízos sofridos, também uma função preventiva, no sentido de evitar-se o dano." (PADILHA, 2010, p. 285). A Lei da Ação Civil Pública (Lei 7.347/1985), em seu artigo 13 prevê que qualquer reparação monetária com relação ao dano ambiental deve ser revertida para o Fundo de Reparação de Bens Lesados.

2) Responsabilidade Administrativa Ambiental: se caracteriza pela imposição de uma sanção administrativa ao agente causador do dano ambiental, sanção esta que é expressão do ius puniendi do Estado, exercício do Poder de Polícia desencadeado pela infração às normas ambientais praticadas pelo agente. Esta responsabilidade fundamenta-se na capacidade que têm as pessoas jurídicas de Direito Público de impor a conduta aos administrados. Esse poder de controle administrativo é inerente à Administração de todas as entidades estatais - União, Estados, Distrito Federal e Municípios -, nos limites das respectivas competências institucionais.

No que se refere ao poder de polícia ambiental, a proteção do meio ambiente exige a necessária intervenção do Poder Público, restringindo e condicionando direitos individuais, inclusive o direito de propriedade, que deve atender uma função socioambiental, em prol da manutenção do equilíbrio de meio ambientem enquanto um bem de natureza difusa, portanto, do interesse de toda a coletividade e que tem prevalência sobre o interesse individual (PADILHA, 2010, p. 287).

A base legal para o exercício do poder de polícia ambiental encontra-se no artigo 70 da Lei $n^{\circ} 9.605 / 98$, onde no seu $\S 1^{\circ}$ define que "são autoridades competentes para lavrar auto de infração ambiental e instaurar processo administrativo os funcionários de órgãos ambientais integrantes do Sistema Nacional de Meio Ambiente - SISNAMA, designados para as atividades de fiscalização, bem como os agentes das Capitanias dos Portos, do Ministério da Marinha".

A responsabilidade administrativa ambiental, dentro da classificação dos tipos de responsabilidade, é extracontratual subjetiva, sendo esta a regra adotada pelo ordenamento pátrio, ou seja, dependente de prova da intencionalidade do agente (dolo ou culpa). 
A Lei que fixa sanções administrativas (e penais) em matéria ambiental é a Lei no 9.605/98. Esta lei dispõe sobre as sanções penais e administrativas derivadas de condutas e atividades lesivas ao meio ambiente.

A Lei no 9.605 veio a ser regulamentada, para o nível federal, pelo Decreto $\mathrm{n}^{0}$ 3.179/99, que foi revogado pelo Decreto n 6.514/2008 e manteve-se dentro dos cânones constitucionais, não atropelando as competências estaduais e/ou municipais quanto à aplicação das sanções administrativas ambientais.

Esta Lei, na parte da infração administrativa, pode ser suplementada pelos Estados e municípios. O uso da competência suplementar deve conduzir a modificações que não alterem a finalidade da norma geral federal.

Sobre a infração administrativa ambiental, podemos dizer que é toda ação ou omissão que viole as regras jurídicas de uso, gozo, promoção, proteção e recuperação do meio ambiente. As regras jurídicas devem estar expressas em algum texto, devidamente publicado. O auto de infração deverá apontar a regra jurídica violada.

As infrações administrativas são apuradas em processo administrativo próprio, segundo o critério de ampla defesa e contraditório, observando-se as disposições da Lei no 9.605/98.

As infrações administrativas praticadas contra o meio ambiente vem tipificadas no Decreto nº 3.179/99 e se dividem em: I - infrações contra a fauna; II Infrações contra a flora; III - poluição e outras infrações administrativas típicas ambientais; IV - infrações contra o ordenamento urbano e o patrimônio cultural; V - infrações contra a administração ambiental.

A Lei no 9.605/98 estatui, no seu artigo 72 que as infrações administrativas, levando em conta as circunstâncias de gravidade, antecedentes e situação econômica, são punidas com as seguintes sanções: I - advertência; II - multa simples; III - multa diária; IV - apreensão dos animais, produtos e subprodutos da fauna e flora, instrumentos, petrechos, equipamentos ou veículos de qualquer natureza utilizados na infração; V destruição ou inutilização do produto; VI - suspensão de venda e fabricação do produto; VII - embargo de obra ou atividade; VIII - demolição de obra; IX - suspensão parcial ou total de atividades; $\mathrm{X}$ - restritivas de direitos, observadas as normas constantes dos parágrafos $1^{\circ}$ ao $7^{\circ}$. 
As referidas sanções são executáveis independentemente de autorização judicial, em virtude da auto-executoriedade dos atos de polícia, devendo, a cada sanção a ser aplicada, estar presente a proporcionalidade entre ela e a infração cometida.

Das 10 sanções previstas no artigo 72 da Lei no 9.605/98, somente a multa simples utilizará o critério da responsabilidade com culpa; e as outras nove sanções, inclusive a multa diária, irão utilizar o critério da responsabilidade se culpa ou objetiva, continuando a seguir o sistema da Lei n 6.938/81, onde não há necessidade de serem aferidos o dolo e a negligência do infrator submetido ao processo.

A aplicações de sanções administrativas requer a instauração do respectivo processo administrativo punitivo, necessariamente contraditório, com oportunidade de defesa e estrita observância do devido processo legal, sob pena de nulidade da punição imposta, nos estritos termos do artigo 5ำ LV, da Constituição. Tudo isso deve realizar-se com observância dos prazos dispostos no artigo 71 da Lei nº 9.605/98.

\section{3) Responsabilidade Penal Ambiental: A previsão de crimes} especificamente ecológicos, esteja ela compreendida no Código Penal ou expressa em leis especiais é, de qualquer modo, a única forma para assegurar aos valores ambientais aquela proteção "imediata" de que necessitam no momento atual, surgindo, "assim, no direito penal recente, uma tipologia de seus interesses ecológicos que se apresentam sempre, em todas as experiências legislativas que se vêm a fazer na matéria. (MUKAI, 2002, p. 79).

Quanto ao crime de dano ecológico, ocorre sempre que a tutela emprestada ao bem natural considere o momento em que se verificam os efeitos da inquinação e o dano constitui-se numa alteração da situação preexistente em razão da ação de determinado sujeito, o crime comportará a valoração da lesão efetiva de um bem ambiental. Por isso, hipóteses de crimes de danos, nesse campo, não são frequentes, porque, na prática, são de difícil aplicação. (MUKAI, 2002, p. 79).

Nos tempos modernos, a tendência é antecipar a proteção do ambiente natural, do momento do dano ao momento do exercício da atividade perigosa aos bens ecológicos, quando não do instante da simples detenção ou produção de substâncias poluentes. A atenção do legislador tem sido cada vez mais nesse sentido, obcecada que se acha pela necessidade de prevenir o fenômeno, reprimindo as condutas predatórias. 
Afastam-se os crimes ecológicos, consequentemente, sempre mais da lesão efetiva do bem jurídico, para construírem uma linha avançada de defesa contra a poluição.

Mas na doutrina mais atenta e nas experiências legislativas de vanguarda vai se afirmando outro modo de considerar o problema. Partidas das dificuldades sabidas de encontrar o legislador penal, para delimitar o âmbito e a intensidade da tutela a ser emprestada aos bens ambientais, sugere-se que a proteção do ambiente seja confiada principalmente à autoridade administrativa, a quem cabe a obrigação de regulamentar os fatores poluentes, de conceder autorizações para o exercício de atividades perigosas, de impor limitações, cautelas e proibições com relação a eles. O Direito Penal viria a desenvolver a função secundária de punir a violação de prescrições administrativas.

A Lei no 9.605/98 veio dispor sobre as sanções penais e administrativas, derivadas de condutas e atividades lesivas ao meio ambiente. Esta Lei veio completar a Lei no 7.804/89, regulamentando o art. 225 da Constituição Federal, disciplinando os crimes ecológicos com maiores detalhamentos, fixando a responsabilidade penal e administrativa das pessoas jurídicas e contemplando normas gerais relativas às sanções administrativas.

O Capítulo V desta Lei dispõe, especificamente, sobre os "Crimes contra o Meio Ambiente". Aqui, são elencados os tipos penais relacionados aos crimes ambientais. A Lei no 9.605/98 teve como inovações marcantes, tais como: a não utilização do encarceramento como norma geral para as pessoas físicas criminosas; a responsabilização penal das pessoas jurídicas; e a valorização da intervenção da Administração Pública, através de autorizações, licenças e permissões. Salvo disposições específicas, a responsabilidade penal por dano ambiental se exaure através da aplicação das regras do direito penal, conforme disposição expressa do artigo 79 da Lei nº 9.605/98, que determina aplicação subsidiária do Código Penal e do Código de Processo Penal.

A autoria do crime ambiental tem dimensão própria. O artigo $2^{\circ}$ da Lei $n^{\circ}$ 9.605/98 elege o autor do crime e estende este conceito aos agentes do Estado e da pessoa jurídica que, tendo conhecimento da infração, deixaram de impedir a sua prática. A qualidade do meio ambiente é um valor fundamental, é um bem jurídico de alta relevância, na medida mesma em que a Constituição o considera bem de uso comum do povo, essencial à sadia qualidade de vida, que o Poder Público e a coletividade devem defender 
e preservar. A ofensa a tal bem se revela grave e deve ser definida como crime. A Constituição declara que as condutas e atividades consideradas lesivas ao meio ambiente sujeitarão os infratores a sanções penais (artigo 225, §3º). Deixa à lei definir tais infrações como crime ou contravenção.

A Lei $n^{\circ}$ 9.605/98 estabeleceu quais as condutas que seriam consideradas como crimes, agrupando-as conforme o meio ambiente atingido. Assim, as condutas ficaram divididas em: I - crimes contra a fauna; II - crimes contra a flora; III - poluição e outros crimes ambientais; IV - crimes contra o ordenamento urbano e o patrimônio cultural; V - crimes contra a administração ambiental.

\section{CONSIDERAÇÕES FINAIS}

Como o Direito Ambiental é assunto recente, há uma falsa impressão de que a degradação ao meio ambiente é algo da modernidade. Mas, como muito bem apontado por Milaré (2011, p. 1120) "a devastação ambiental não é privilégio de nossos dias. É um fenômeno que acompanha o homem desde os primórdios de sua história". De fato, os danos ambientais sempre existiram no mundo habitável, apenas recentemente o meio ambiente ganhou holofotes no mundo e, no Brasil, com a Constituição Federal de 1988.

Um exemplo de devastação ambiental foi a construção da Usina Hidrelétrica de Capivara, que foi inaugurada em 1977, que priorizou o desenvolvimento energético em prejuízo das comunidades ribeirinhas e das cidades atingidas pela barragem, causando grandes impactos ambientais na região. As obras foram feitas em um momento em que a legislação não amparava os danos ambientais.

Assim, fácil concluir que o dano ambiental faz parte da vida humana na terra, independentemente da existência de leis. Diferentemente do instituto da reparação/indenização, que depende da previsão legal de proteção jurídica de um bem, para após, ocorrendo um dano/lesão a esse bem tutelado, haverá o pressuposto necessário da obrigação de reparar e, por conseguinte, elemento imprescindível para estabelecer a responsabilidade civil. 


\section{REFERÊNCIAS}

ANTUNES, Paulo de Bessa. Direito Ambiental. 15. ed. São Paulo: Atlas, 2013.

FIORILLO, Celso Antonio Pacheco. Curso de Direito Ambiental Brasileiro. 14. ed.São Paulo: Saraiva, 2013.

LEITE, José Rubens Morato. Dano Ambiental: do individual ao coletivo extrapatrimonial. 5. ed. São Paulo: Revista dos Tribunais, 2012.

MILARÉ, Édis. Direito do ambiente: a gestão ambiental em foco: doutrina, jurisprudência, glossário. 7. ed. São Paulo: Revista dos Tribunais, 2011.

MUKAl, Toshio. Direito ambiental sistematizado. 4. ed. Rio de Janeiro: Forense Universitária, 2002.

PADILHA, Norma Sueli. Fundamentos Constitucionais do Direito Ambiental Brasileiro. Rio de Janeiro: Elsevier, 2010.

SARLET, Ingo Wolfgang e FENSTERSEIFER, Tiago. Direito Constitucional Ambiental. 2. ed. São Paulo: Revista dos Tribunais, 2012.

THOMÉ, Romeu. Manual de Direito Ambiental. 2. ed. Bahia: Editora Juspodivm, 2012. 